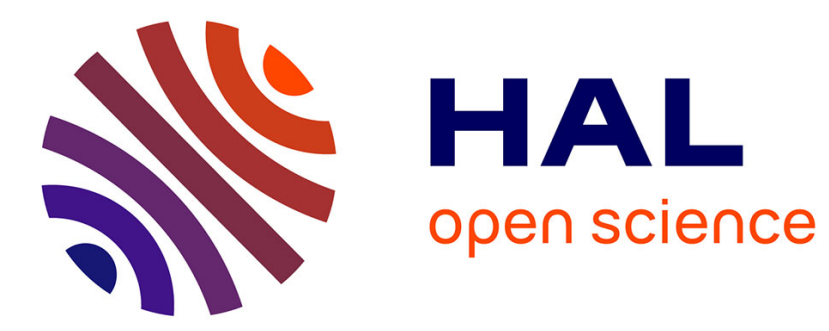

\title{
Seasonal Predictability and Spatial Coherence of Rainfall Characteristics in the Tropical Setting of Senegal
}

\author{
Vincent Moron, Andrew W Robertson, M. Neil Ward
}

\section{To cite this version:}

Vincent Moron, Andrew W Robertson, M. Neil Ward. Seasonal Predictability and Spatial Coherence of Rainfall Characteristics in the Tropical Setting of Senegal. Monthly Weather Review, 2006, 134 (11), pp.3248-3262. 10.1175/MWR3252.1 . hal-02894978

\section{HAL Id: hal-02894978 https://hal.science/hal-02894978}

Submitted on 9 Jun 2021

HAL is a multi-disciplinary open access archive for the deposit and dissemination of scientific research documents, whether they are published or not. The documents may come from teaching and research institutions in France or abroad, or from public or private research centers.
L'archive ouverte pluridisciplinaire HAL, est destinée au dépôt et à la diffusion de documents scientifiques de niveau recherche, publiés ou non, émanant des établissements d'enseignement et de recherche français ou étrangers, des laboratoires publics ou privés. 


\title{
Seasonal Predictability and Spatial Coherence of Rainfall Characteristics in the Tropical Setting of Senegal
}

\author{
Vincent Moron,* Andrew W. Robertson, And M. Neil Ward \\ International Research Institute for Climate and Society, The Earth Institute at Columbia University, Palisades, New York
}

(Manuscript received 30 August 2005, in final form 8 March 2006)

\begin{abstract}
This study examines space-time characteristics of seasonal rainfall predictability in a tropical region by analyzing observed data and model simulations over Senegal. Predictability is analyzed in terms of the spatial coherence of observed interannual variability at the station scale, and within-ensemble coherence of general circulation model (GCM) simulations with observed sea surface temperatures (SSTs) prescribed. Seasonal mean rainfall anomalies are decomposed in terms of daily rainfall frequency and daily mean intensity. The observed spatial coherence is computed from a 13-station network of daily rainfall during the July-September season 1961-98 in terms of (i) interannual variability of a standardized anomaly index (i.e., the average of the normalized anomalies of each station), (ii) the external variance (i.e., the fraction of common variance among stations), and (iii) the number of spatiotemporal degrees of freedom. Spatial coherence of interannual anomalies across stations is found to be much stronger for seasonal rainfall amount and daily occurrence frequency, compared with daily mean intensity of rainfall. Combinatorial analysis of the station observations suggests that, for occurrence and seasonal amount, the empirical number of spatial degrees of freedom is largely insensitive to the number of stations considered, and is between 3 and 4 for Senegal. For daily mean intensity, by contrast, each station is found to convey almost independent information, and the number of degrees of freedom would be expected to increase for a denser network of stations. The GCM estimates of potential predictability and skill associated with the SST forcing are found to be remarkably consistent with those inferred from the observed spatial coherence: there is a moderateto-strong skill at reproducing the interannual variations of seasonal amounts and rainfall occurrence, whereas the skill is weak for the mean intensity of rainfall. Over Senegal during July-September, it is concluded that (i) regional-scale seasonal amount and rainfall occurrence frequency are predictable from SSTs, (ii) daily mean intensity of rainfall is spatially incoherent and largely unpredictable at the regional scale, and (iii) point-score estimates of seasonal rainfall predictability and skill are subject to large sampling variability.
\end{abstract}

\section{Introduction}

Potential users of seasonal to interannual climate predictions are often interested in forecasts of seasonal rainfall totals at the local scale. In addition, withinseason rainfall characteristics, such as rainfall occurrence frequency and intensity can be of particular concern; the frequency and length of dry spells, for ex-

\footnotetext{
* Additional affiliation: UFR des Sciences Géographiques et de l'Aménagement, Université d'Aix-Marseille I, and CEREGE, UMR-6635, CNRS, France.

Corresponding author address: Vincent Moron, CEREGE, UMR 6635, Europôle Méditerranéen de l'Arbois, BP 80, 13545 Aix en Provence, France.

E-mail: moron@cerege.fr
}

ample, are important to agriculture (Ingram et al. 2002). Seasonal mean rainfall can be decomposed as the product of daily rainfall occurrence frequency and average daily rainfall intensity. Seasonal predictability of seasonal amounts may thus translate into predictability of occurrence and mean intensity, with useful consequences for agricultural planning. On the other hand, the spatial scales of the processes determining rainfall occurrence and intensity may be different, with important implications for the skill of seasonal forecasts at the local scale. Indeed, evidence from downscaled general circulation model (GCM) simulations of rainfall over Queensland, Australia, suggests that intensity is much less predictable than rainfall occurrence frequency or seasonal rainfall amount (Robertson et al. 2006). For the Sahel region of West Africa, previous studies have found that the main source of the seasonal 
rainfall variability is associated with the variability in the number of rainy events rather than the magnitude of the events (D'Amato and Lebel 1998; Laurent et al. 1998). Le Barbe and Lebel (1997) and Le Barbe et al. (2002) have shown that, in the central Sahel, most of the rainfall reduction for the period $1970-89$ is explained by a decrease in the number of rain events, whereas the average storm rainfall did not vary much.

The goal of this paper is to better understand seasonal predictability of rainfall amount, occurrence, and mean intensity at the station level, using observed daily rainfall from 13 stations over Senegal, together with an ensemble of atmospheric GCM simulations in which observed sea surface temperatures (SSTs) are prescribed. Potential predictability is often assessed using ensembles of GCM simulations, run from slightly differing initial conditions, but with identical SST boundary conditions prescribed. The common response among ensemble members is then compared with the spread between them to estimate the signal-to-noise ratio (SNR). This is often estimated in terms of ensemble mean versus within-ensemble variance (Rowell et al. 1995; Zwiers 1996; Rowell 1998) of seasonal averages, or by identifying spatial patterns that maximize the SNR (Venzke et al. 1999). A large SNR is characterized by large coherence between GCM ensemble members.

An analogous approach can be taken to analyze an observed daily rainfall network, over a relatively small, homogenous region. In this case it is assumed that the stations are situated far enough apart to be independent of each other, as far as local processes are concerned, but that all experience the same large-scale climate forcing from anomalous SST. High spatial coherence between stations indicates potential predictability in terms of the large-scale climate anomalies, which in the case of GCM ensemble averages, may be attributed to forcing from SST anomalies. In both cases, actual predictability is contingent on being able to predict these "forcing" anomalies, yielding estimates of potential predictability. Weak spatial coherence implies small potential predictability, but the converse is not necessarily true; for example, the North Atlantic Oscillation (NAO) is largely unpredictable at the seasonal scale (Marshall et al. 2001), yet may lead to high spatial coherence of interannual anomalies between stations.

The spatial SNR ratio can be considered as a spatial analog of the established temporal-scale separation into slow (i.e., month to seasonal) climatic "signal" and synoptic-scale weather "noise" (Leith 1974; Madden 1976; Zwiers 1987). Observational estimates of potential predictability have been derived using a "one-way" analysis of variance that splits the total variance into a signal component, given by the interannual variance of the seasonal mean, versus a noise component, usually estimated through the spectral density function of daily data at nonzero frequencies (Madden 1976; Zwiers 1987). The spatial coherence of a field can also be quantified by estimating the number of spatial degrees of freedom (Fraedrich et al. 1995; Bretherton et al. 1999), or by calculating the interannual variance of a spatial average of standardized anomalies (Katz and Glantz 1986); if the anomalies are uncorrelated, then the interannual variability of their spatial average will be small.

In addition to providing an estimate of potential predictability, GCM simulations forced by historical SSTs can be used to estimate hindcast skill that would be achieved with a perfect forecast of SST (Gates 1992; Sperber and Palmer 1996). To make GCM hindcasts of Senegal seasonal rainfall at the station level, it is necessary to calibrate the GCM output, to take into account model biases. In this paper we use a model output statistics (MOS) correction, derived from a canonical correlation analysis (CCA) between the model field and observed Senegal network of rainfall station, using seasonal-averaged quantities (Ward and Navarra 1997; Moron et al. 2001). The GCM estimates of potential predictability and simulation skill are then compared with those inferred from the analysis of observed spatial coherence between rainfall stations over Senegal.

The paper proceeds as follows. Section 2 describes the data and section 3 details the methods used. The analysis of spatial coherence in the observed station dataset is reported in section 4 . The link between spatial coherence and potential predictability is discussed in section 5. In section 6, we describe the potential predictability and skill of the GCM simulations for Senegal. Conclusions are given in section 7 .

\section{Data}

\section{a. Station rainfall data}

A 13-station network of observed daily rainfall, obtained from the Direction de la Météorologie Nationale (DMN) of Senegal, is used in this study, for the JulySeptember (JAS) season, 1961-98. Senegal is relatively flat and vegetation type is the main source of landscape heterogeneity across the country. Shrub and tree steppes dominate in the north $(<500 \mathrm{~mm}$ rainfall), savanna woodlands dominate in the central section (500$700 \mathrm{~mm}$ rainfall), with dense savanna and increasing forest toward the humid south ( $>700 \mathrm{~mm}$ rainfall). The network includes the main "synoptic" stations of Senegal but also three others ones (Kounghel, Diouloulou, and Goudiry). Measurements at the former stations are automatic, while those carried out at the latter ones are 
(a) location map

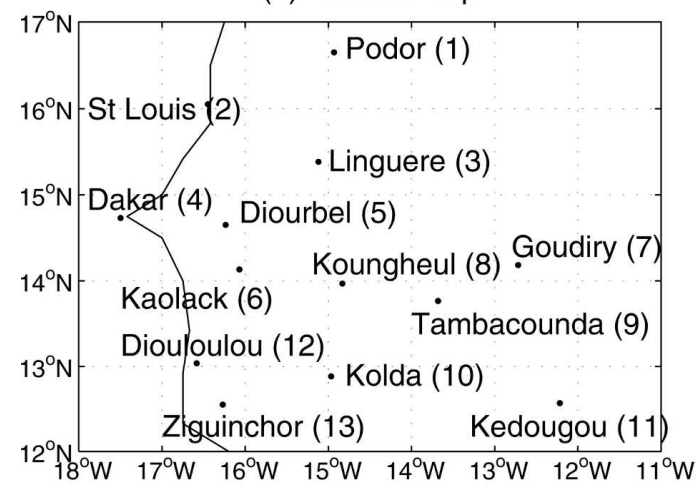

(c) occurrence of rainfall (in day)

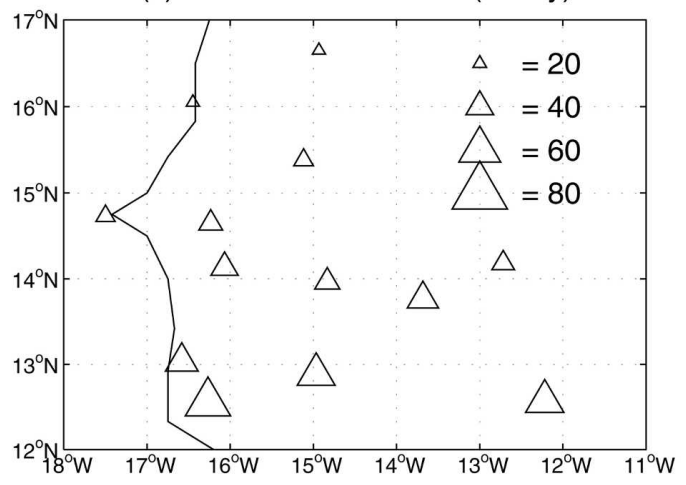

(b) seasonal amount (in $\mathrm{mm}$ )

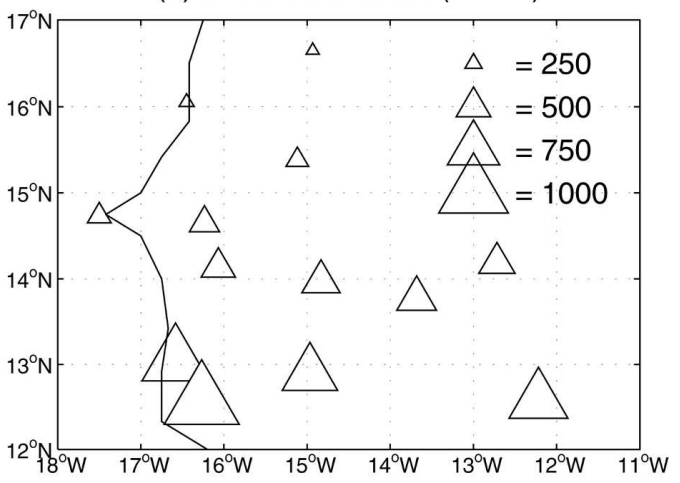

(d) mean intensity (in $\mathrm{mm} /$ day)

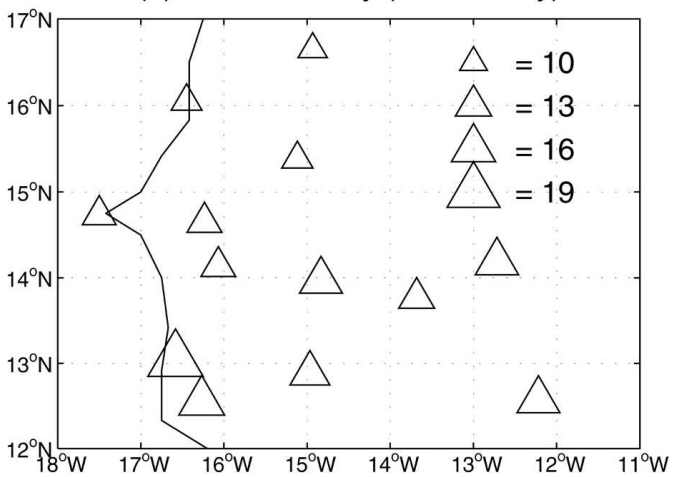

(e) simulated seasonal amount (in $\mathrm{mm}$ )

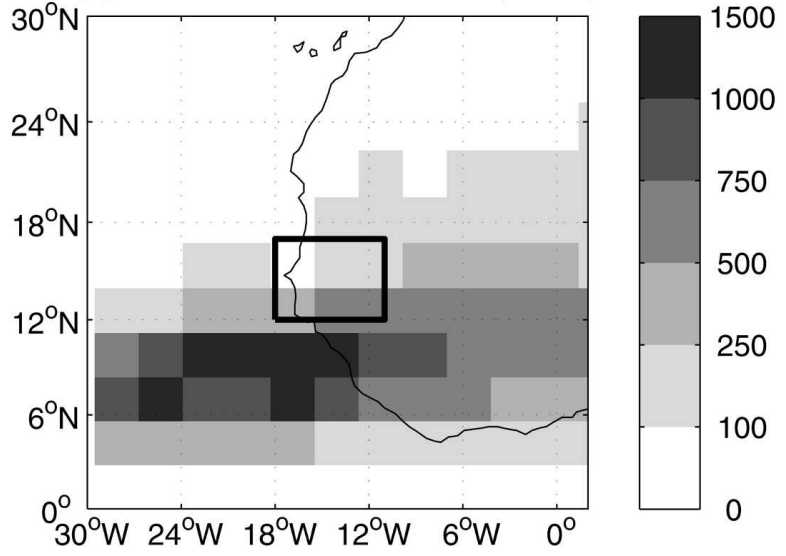

FIG. 1. (a) Location of the 13 stations used in this study; (b) seasonal amount (mm during JAS); (c) rainfall occurrence (number of rainy days receiving $>0 \mathrm{~mm}$ ); (d) daily mean intensity of rainfall $\left(\mathrm{mm} \mathrm{day}^{-1}\right.$ ) during the wet day; and (e) seasonal amount (mm during JAS) for the 24-member ensemble of ECHAM 4.5. The black box represents the window used in other panels.

done manually. The JAS season accounts for between $75 \%$ of the annual rainfall in the south to more than $90 \%$ in the north. Figure 1 shows the station locations, along with the climatological seasonal amount, occurrence frequency, and daily mean intensity on wet days (i.e., seasonal amount divided by the number of wet days). The largest seasonal amounts and occurrences occur in the southwest decreasing northward, consis- tent with the large-scale rainfall pattern associated with the intertropical convergence zone (ITCZ; Camberlin and Diop 1999). This is associated with a rainy season, which is centered on August and is shorter in the north. There is also a secondary west-east rainfall gradient from the coast, in the central and northern part of the country (Figs. 1b,c), partly related to the coastal influence of the cold Canary Current. 
The spatial variability of seasonal amount (Fig. 1b) and daily rainfall occurrence (Fig. 1c) is larger than that of the daily mean intensity of rainfall (Fig. 1d). The daily mean intensity of rainfall (Fig. 1d) should not be confused with the rain rate, which depends basically on the nature (i.e., stratiform or convective) of rainfall. In Senegal, as for the entire Sahel, most of rainfall is associated with westward-moving mesoscale convective systems (Laurent et al. 1998; Mathon and Laurent 2001) embedded in the ITCZ. The mean rain rate is thus high (near $5 \mathrm{~mm} \mathrm{~h}^{-1}$ in the Dakar area for 1993 99; Nzeukou and Sauvageot 2002) and more than $75 \%$ of the total seasonal rainfall amount typically falls in less than $10 \mathrm{~h}$, corresponding to the convective part of the squall lines (Kebe et al. 2005). Thus, the climatological daily mean intensity plotted in Fig. 1d reflects the average duration of rainfall at each station on wet days, together with the average rain rate.

It is possible that rainfall occurrence (daily mean intensity) could be underestimated (overestimated) at the three nonsynoptic stations. These stations record fewer very small amounts (i.e., daily rainfall $<1 \mathrm{~mm}$ ) than the surrounding stations (Fig. 1c) and this smaller number of wet days increases their mean intensity (Fig. 1d). For example, Diouloulou has only 86 rainy days receiving less than $1 \mathrm{~mm}$ while 440 such days are observed in Ziguinchor (Fig. 1a). However, considering a threshold of $1 \mathrm{~mm}$ to define wet days instead of $0 \mathrm{~mm}$ does not noticeably change the results (not shown). We assume that any measurement errors have no reason to be spatially coherent and thus only contribute to the noise component of each station's variability.

\section{b. Simulated rainfall data}

A 24-member ensemble of simulations made with the European Centre-Hamburg Model (ECHAM-4.5) atmospheric GCM (Roeckner et al. 1996) is analyzed, over the same period, with observed SSTs prescribed. Each simulation differs only in its January 1950 initial condition. The model was run at T42 (approx 2.8 ${ }^{\circ}$ ) resolution, and the simulations have been described extensively elsewhere (e.g., Gong et al. 2003). Daily simulated rainfall amounts were extracted within a window $\left(0^{\circ}-30^{\circ} \mathrm{N}, 30^{\circ} \mathrm{W}-0^{\circ}\right)$. Figure $1 \mathrm{e}$ displays the mean seasonal rainfall amount simulated by the model. The main north-south, and the secondary west-east, rainfall gradients are captured reasonably well, although the rainfall is clearly underestimated over Senegal, with simulated amounts from $<100 \mathrm{~mm}$ in the northwest to $>700 \mathrm{~mm}$ in the southeast (Fig. 1e). As is typical in GCMs, rainfall occurrence is strongly overestimated (not shown). The number of rainy days $>0 \mathrm{~mm}$ varies between 70 in the north to 92 in the south; this bias is mainly due to very small amounts and considering a threshold of $1 \mathrm{~mm}$ to define wet days leads to a quite realistic climatology with around 20 days in the northwest to 70-80 in the south (not shown).

\section{Methods}

\section{a. Estimation of the spatial coherence between stations}

Our main hypothesis is that the seasonal averages of rainfall amount $S$, occurrence $O$, and mean intensity $I$ at each station can be decomposed into a spatially uniform signal and a stochastic spatially independent noise. The signal is estimated by the spatial coherence among the 13-station network computed using three different measures: interannual variance of the standardized anomaly index (Katz and Glantz 1986), "external" variance (Zwiers 1996; Rowell 1998), and degrees of freedom (Fraedrich et al. 1995) of $S, O$, and $I$ matrices. We write the individual station time series of $S, O$, and $I$ as $x_{i j}$, where $i=1, \ldots, N$ denotes the year and $j=1, \ldots, M$ denotes the station, and the $N \times M$ matrices of $S, O$, and $I$ as $\mathbf{X}$. These are first normalized to zero mean and unit variance

$$
x_{i j}^{\prime}=\frac{\left(x_{i j}-\bar{x}_{j}\right)}{\sigma_{j}},
$$

where $\bar{x}_{j}$ is the long-term time mean and $\sigma_{j}$ is the interannual standard deviation for station $j$. The standardized anomaly index (SAI) is defined as the average of the normalized station time series of seasonal averages over the $M$ stations (Katz and Glantz 1986):

$$
\mathrm{SAI}_{i}=\frac{1}{M} \sum_{i=1}^{M} x_{i j}^{\prime}
$$

The interannual variance of the SAI [var(SAI)] is a measure of the spatial coherence because it depends on the interstation correlations $\rho$. Substitution into the general expansion for the variance of a linear combination of correlated variables (e.g., Hogg and Craig 1970) gives

$$
\operatorname{var}(\mathrm{SAI})=\frac{1}{M}+\left(1-\frac{1}{M}\right) \bar{\rho},
$$

where $\bar{\rho}$ is the spatial mean of the interstation correlations. If all correlations are zero, then $\bar{\rho}=0$ and var$(\mathrm{SAI})=1 / M$; if all pairs of stations are perfectly correlated, then $\bar{\rho}=1$ and $\operatorname{var}(\mathrm{SAI})=1$ (Katz and Glantz 1986).

The var(SAI) estimate is closely related to the definition of "external variance" ratio (EVR) used in SST- 
forced GCM experiments (Zwiers 1996; Rowell 1998) discussed in section $3 \mathrm{~b}$, and defined as

$$
\mathrm{EVR}=\frac{\sigma_{\mathrm{EXT}}^{2}}{\sigma_{\mathrm{EXT}}^{2}+\sigma_{\mathrm{INT}}^{2}} .
$$

Here, $\sigma_{\text {EXT }}^{2}$ and $\sigma_{\text {INT }}^{2}$ are defined respectively as the external variance that is common to all stations and the "internal" variance that is associated with differences between stations,

$$
\begin{aligned}
\sigma_{\mathrm{EXT}}^{2} & =\operatorname{var}(\mathrm{SAI})-\left(\frac{1}{M} \sigma_{\mathrm{INT}}^{2}\right) \\
\sigma_{\mathrm{INT}}^{2} & =\frac{1}{N(M-1)} \sum_{j=1}^{M} \sum_{i=1}^{N}\left(x_{i j}^{\prime}-\mathrm{SAI}_{i}\right)^{2} .
\end{aligned}
$$

The empirical EVR and var(SAI) are thus related estimates of the spatial coherence, and thus of the amount of common signal in the station data. The difference between var(SAI) and EVR grows as the part of the internal component of the variance increases and/or as the number of stations decreases.

A third measure of interdependence among stations involves estimating the number of independent variables in the network, or degrees of freedom (Der Megredichtian 1979; Moron 1994; Fraedrich et al. 1995; Bretherton et al. 1999). The number of degrees of freedom (DOF) can be estimated through an eigenanalysis [i.e., empirical orthogonal function (EOF) analysis] of the correlation matrix formed from the station seasonal mean time series,

$$
\mathrm{DOF}=\frac{M^{2}}{\sum_{i=1}^{M} e_{i}^{2}}
$$

where $e_{i}$ are the eigenvalues of the correlation matrix. In the limiting case of $e_{i}=1$ for all stations, $\mathrm{DOF}=M$ (or $\mathrm{DOF}=N-1$ if $N<M$ ), that is, each station conveys independent information and the common signal is zero. On the other hand, if a single eigenvalue accounts for all variance of the field (= trace of the correlation matrix, i.e., $M$ ), then $\mathrm{DOF}=1$ (i.e., each station conveys the same information equal to the signal and the noise is zero). In the latter case, the station network can be described by a single EOF. The DOF depends on the rank of the station matrix (equal to $M$ here) and its sensitivity to the number of stations can be tested by using a combinatorial analysis, in which all possible subsets of stations are constructed for $M=$ $2, \ldots, 13$ (section 4).

The DOF approach is based on two assumptions: that the data are normally distributed and that the co- variance matrix is known with sufficient accuracy (Bretherton et al. 1999). The first assumption can be verified using a Kolmogorov-Smirnov test. For the Senegal network, the lowest asymptotic value of the test equals $0.13,0.23$, and 0.12 , for $S, O$, and $I$, respectively, so that the null hypothesis of a normal distribution is never rejected at the two-sided $90 \%$ confidence level. All calculations have been repeated, using a BoxCox transform (Box and Cox 1964) to prewhiten the rainfall data, with very similar results (not shown). The second assumption is more difficult to verify. Although the station time series are short, the serial correlation of $S$ is always less than 0.19 at all stations: it exceeds 0.26 at one station for $O$ and at three stations for $I$. The influence of temporal persistence is thus relatively small. The effect of finite sample size is estimated explicitly in many of the analyses in sections 4 and 5 .

\section{b. Estimation of the potential predictability and hindcast skill from GCM simulations}

Atmospheric variability is linked to both local processes as well as interactions with other parts of the climate system. In the Tropics, it is well known that a moderate-to-large part of the variability at seasonal and longer time scales is controlled by the slowly evolving SST. A classical way to estimate the amount of SSTforced variance is to perform multiple GCM experiments forced by prescribed historical SST and differing only by their initial conditions (i.e., Gates 1992). The EVR can then be used to separate SST-forced external variance, which is common to all ensemble members from the internal chaotic variance, defined as the difference between ensemble members. In the GCM context, the EVR is estimated at each grid point using Eq. (4) and (5), with $M$ being the number of ensemble members, instead of the number of stations.

The external variance is potentially predictable from the SST and defines the highest skill attainable by the GCM in terms of the correlation between observed and simulated atmospheric time series (Rowell 1998). However, $\sigma_{\mathrm{EXT}}^{2}$ does not necessarily translate fully into skill; for example, the GCM may displace teleconnection patterns relative to the observed climate. This spatial bias can be easily corrected by postprocessing the GCM outputs, using a MOS correction, such as CCA (Barnett and Preisendorfer 1987). A CCA is computed here between the 13 station time series and the GCM gridpoint time series of precipitation within the region $\left(0^{\circ}-30^{\circ} \mathrm{N}\right.$, $30^{\circ} \mathrm{W}-0^{\circ}$ ). A larger $\mathrm{GCM}$ window yields very similar results while a smaller window degrades it. The CCA is repeated 3 times, using $S, O$, and $I$ constructed from both station data and GCM simulations. Simulated $O$ 

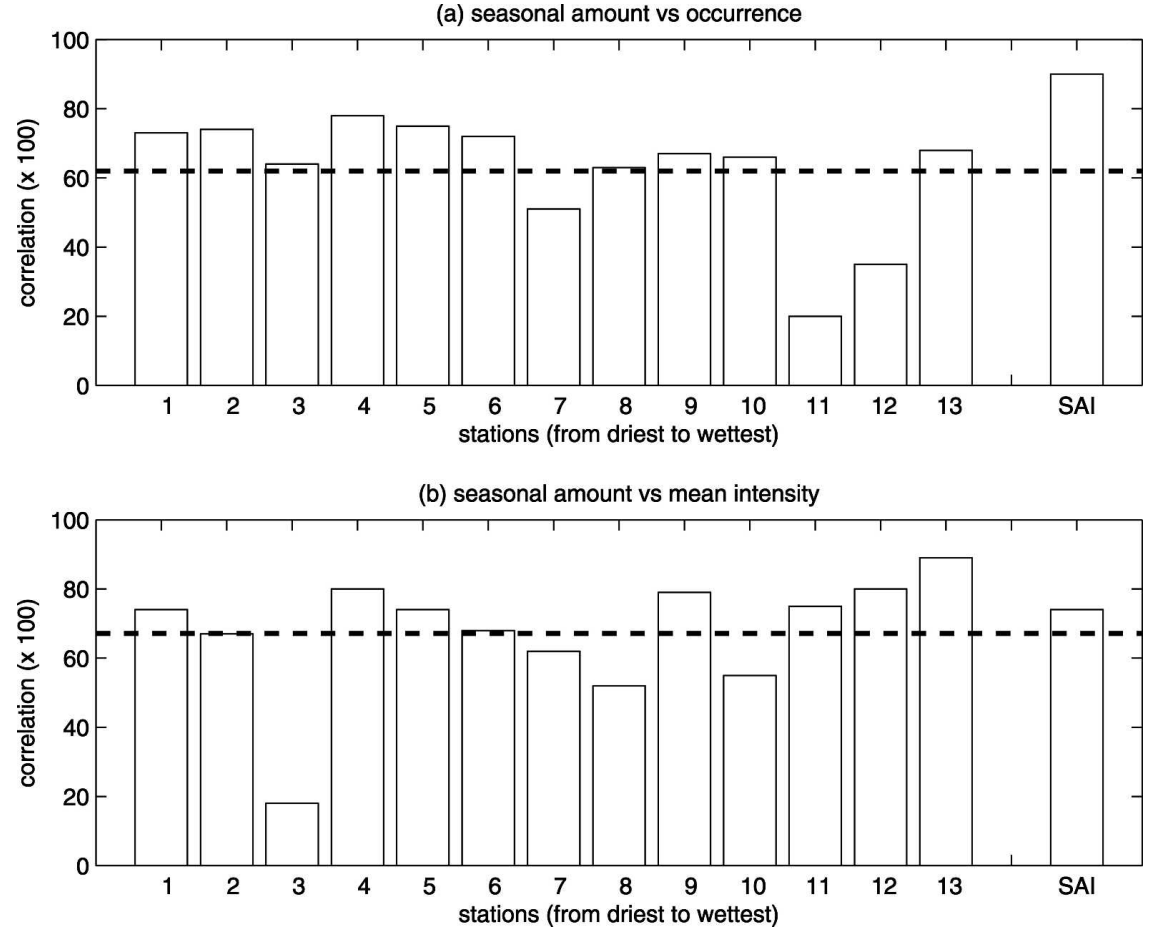

FIG. 2. Temporal correlation $(\times 100)$ (a) between seasonal amount and rainfall occurrence and (b) between seasonal amount and mean intensity for each station. The 13 stations are ranked from the driest to the wettest one (the numbers refer to Fig. 1a) and the last column gives the correlation between the SAI of (a) seasonal amount and rainfall occurrence and of (b) seasonal amount and mean intensity. The horizontal dashed line indicates the country average of the correlations between (a) seasonal amount and rainfall occurrence and (b) seasonal amount and mean intensity.

and $I$ are computed using a GCM precipitation threshold of $1 \mathrm{~mm} \mathrm{day}^{-1}$.

All 24 members of the ensemble were used without forming the ensemble mean, following the method of Ward and Navarra (1997) and Moron et al. (2001). The analysis proceeds by first expanding each field into principal components (PCs) and then performing the CCA in the reduced subspace of the two sets of PCs explaining $75 \%$ of the variance of each field. Cross validation was employed, dividing the datasets into a 33-yr training and a 5-yr validation part, and repeating the analysis 8 times. The number of the CCA modes retained was chosen so as to maximize the correlation between observed and simulated ensemble mean SAI under cross validation.

\section{Analysis of station data}

a. Correlations between seasonal amount, occurrence, and intensity

Cross correlations between $S$, and $O$ and $I$, are displayed in Fig. 2 for each station and the SAI. At the local scale, seasonal total correlates on average (Fig. 2, dashed line) rather equally with occurrence and mean intensity. However, we contend in this paper that occurrence is more strongly tied to the large-scale (and potentially predictable) climate signals. This is the proposed reason why the SAI area-averaged indices of $S$ and $O$ (Fig. 2a, last bar) correlate more strongly than those of $S$ and $I$ (Fig. 2b, last bar). When occurrence is averaged across stations, the noise at each station cancels, making the large-scale signal more visible in the area-averaged index (Fig. 2).

For the wettest stations, the correlations between $S$ and $I$ (Fig. 2b) are usually larger than those between $S$ and $O$ (Fig. 2a). The correlation between $I$ and $O$ for the SAI is weakly positive $(\rho=0.38)$ while the individual correlations between $I$ and $O$ are weak and can be substantially negative (not shown). Such negative correlations could materialize if, for example, relatively dry years tend to consist of a small number of larger events, whereas relatively wet years contain a substantial number of small-to-moderate rainfall events. The quasi independence between $I$ and $O$ is further confirmed by the variance of $S$, explained in a least squares sense, by using $O$ and $I$ as predictors (not shown). The 
(a) seasonal amount

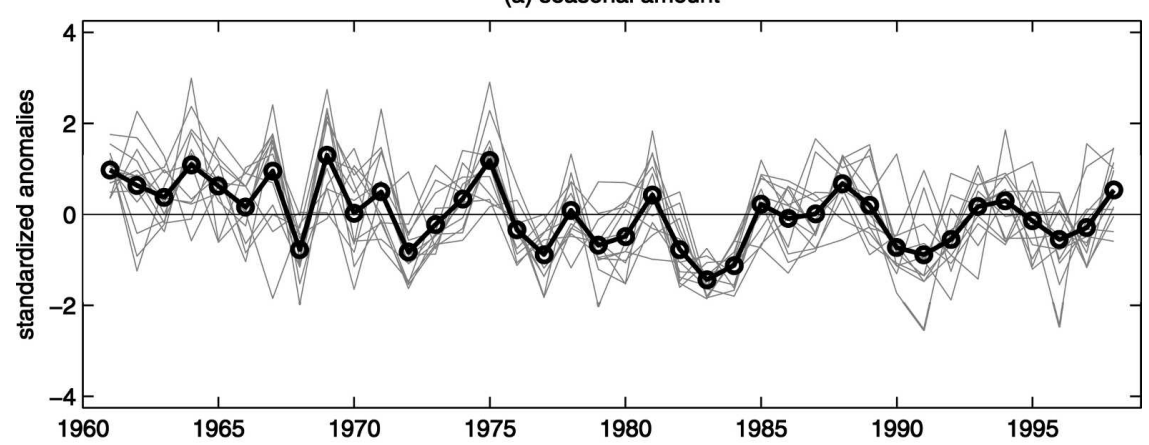

(b) occurence of rainfall

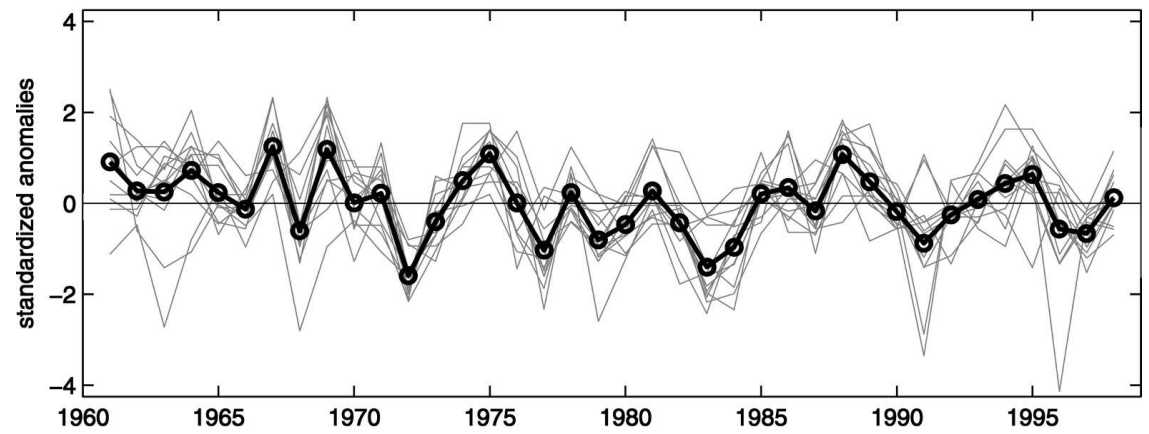

(c) mean intensity of rainfall

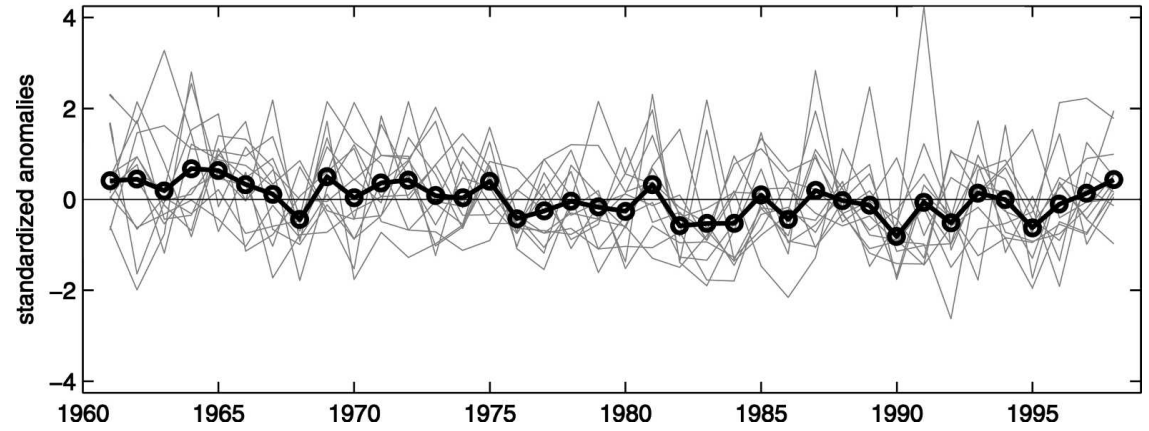

FIG. 3. Normalized anomalies of (a) seasonal amount, (b) rainfall occurrence, and (c) mean intensity of rainfall for the 13 stations of Senegal. The gray lines indicate each station and the boldface line with circles is the standardized anomaly index (= mean of the 13 stations).

proportion of variance of $S$ explained by $O$ and $I$ is greater than $82 \%$ at all stations, and exceeds $97 \%$ at 12 of the 13 stations; it is always much larger than the individual squared correlations displayed in Fig. 2.

\section{b. Spatial coherence}

Figure 3 displays the standardized anomaly time series of $S, O$, and $I$ at each station, together with the SAI of each index (thick line). The level of interstation noise given by the dispersion of the curves, is clearly much stronger for $I$ than for $S$ and $O$. In addition, the interannual variability of SAI is small for $I$, compared with $S$ and $O$, suggesting that the external variance of $I$ is small.

The spatial coherence of $S, O$, and $I$, are compared in Table 1, in terms of the EVR, DOF, and var(SAI) defined in section 3. All three measures yield results consistent with Fig. 2, giving similar values for amount and occurrence, and much smaller coherence for intensity. The EVR and var(SAI) are both about $45 \%$ for occurrence and amount, which suggests potential predictability with anomaly-correlation skills (i.e., the square root of the EVR) exceeding 0.65. For intensity, on the other hand, an EVR of $15 \%$ would indicate a potential 
TABLE 1. The EVR (\%), number of DOF, var(SAI) (\%), and variance explained by the first EOF of $S, O$, and $I$ of the 13-station network.

\begin{tabular}{lccc}
\hline \hline & $S$ & $O$ & $I$ \\
\hline EVR (\%) & 43.6 & 45.1 & 8.0 \\
DOF & 3.81 & 3.26 & 9.33 \\
Var(SAI) (\%) & 47.3 & 48.7 & 14.8 \\
Variance explained by the first EOF (\%) & 47.9 & 52.8 & 19.3 \\
\hline
\end{tabular}

anomaly correlation skill of less than 0.4 . Note that considering the optimal weighted average defined by the first EOF does not greatly exceed the fraction of variance given by the SAI. The DOF is between 3 and 4 for $S$ and $O$, but exceeds 9 for $I$. Computing DOF values computed from seasonal quantities based on a rainfall threshold of $1 \mathrm{~mm}$ instead of $0 \mathrm{~mm}$ leads to very similar results $(3.82,3.09$, and 9.86 for $S, O$, and $I$, respectively). In summary, the various measures of spatial coherence in Table 1 (and Fig. 2) indicate that seasonal amount is only slightly less coherent than occurrence, while mean intensity is highly incoherent.

The number of DOF is constrained by the rank of the correlation matrix, given here by the number of stations. The dependency on $M$ can be estimated by computing the DOF of all possible combinations of 2-12 stations drawn from the 13-station network. The mean, maximum, and minimum DOF of these combinations are displayed in Fig. 4. It is striking that the mean DOF values for $S$ (Fig. 4a) and $O$ (Fig. 4b) increase very slowly with the number of stations considered, while the estimated DOF increases almost linearly for $I$ (Fig. $4 c)$. To estimate statistical significance, an identical combinatorial analysis was carried out using purely random matrices, consisting of 13 linearly independent time series of the same length; the one-sided 0.01, 0.05, and 0.10 levels of significance are displayed in Fig. 4 as dotted lines. In the case of rainfall amount, the DOF values are significant at the 0.01 significance level (i.e., less than $1 \%$ of the random values fall below the worst possible observed DOF) when at least four stations are used (Fig. 4a). The number of stations required for statistically significant DOF estimates of occurrence frequency increases to 5 (Fig. 4b). In contrast, the mean value of DOF for observed mean rainfall intensity is never significant at the 0.05 level (Fig. 4c).

The estimated mean DOF of the random series (dotted lines) is about 9.8 when the 13 -station network is used, rather than 13, due to the finite length of the time series. We have repeated the calculation using longer time series of white and red noise, having the same first-order serial correlations as the 13-station network. The estimated DOF reaches about 12.5 with 13 random time series of white noise length of 300, and slowly asymptotes. This is related to the fact that off-diagonal values of the correlation matrix of random series are not strictly equal to zero. The amplitude of these offdiagonal correlations, relative to the trace of the correlation matrix (equal to $M$ ), decreases, but does not cancel when $N$ increases, so that the estimated DOF tends toward $M$, but does not reach it.

\section{Spatial coherence versus skill}

The DOF, EVR, and var(SAI) in Table 1 all indicate substantial spatial coherence for seasonal mean rainfall amount and daily rainfall occurrence but weak spatial coherence, if any, for the mean intensity of rainfall. This suggests that the signal in the former case may be due to a large-scale external forcing, which is weak or absent in the latter case. We can now reformulate our first hypothesis, that is, that the $N \times M$ matrices $\mathbf{X}$ of $S, O$, and $I$ can be decomposed into a spatially uniform signal matrix $\mathbf{C}$ and a stochastic spatially independent noise matrix $\mathbf{N}$ as

$$
\mathbf{X}=\mathbf{C}+\mathbf{N}
$$

by considering $\mathbf{C}$ to be a function $g(\mathbf{f})$ of some largescale external forcing $\mathbf{f}$ such as SST:

$$
\mathbf{C}=\lg (\mathbf{f}),
$$

where I is the identity matrix. In this section, we consider theoretical examples, in which we construct random matrices $\mathbf{X}$ for 13 synthetic station time series, using Eq. (7). First, an ideal case is analyzed where the influence of $\mathbf{f}$ is perfectly and linearly transmitted to the network of stations (i.e., $\mathbf{C}=\mathbf{I f})$. We define $\mathbf{f}$ to be a white noise random time series of 38 time units and $\mathbf{N}$ to be an additional set of 13 independent white noise time series of 38 time units. The variances of $\mathbf{C}$ and $\mathbf{N}$ are scaled so that the EVR of $\mathbf{X} \approx 1 \%, 5 \%, 10 \%, 20 \%$, $30 \%, 40 \%, 50 \%, 60 \%, 70 \%, 80 \%, 90 \%, 95 \%$, and $99 \%$. The level of skill, given by the correlation between $\mathbf{f}$ and $\mathbf{X}$, is plotted as a function of the square root of EVR in $\mathbf{X}$ in Fig. 5. In other words, the common variance between $\mathbf{X}$ and $\mathbf{f}$ is the amount of signal. In Fig. 5a, we plot the "ensemble skill" in terms of the correlation between $\mathbf{f}$ and the SAI of $\mathbf{X}$, where each dot represents one of the 13000 (i.e., 1000 simulations $\times 13$ different values of EVR) simulations. This measure of skill increases very quickly as the EVR increases; the noise component cancels very rapidly between stations, even for such a small matrix, and even at low EVRs. With an EVR of $10 \%$, the SAI correlation averaged over the 1000 simulations is 0.76 , with a minimum of 0.57 and a maximum of 0.90 . This does not imply, however, that 
(a) seasonal amount

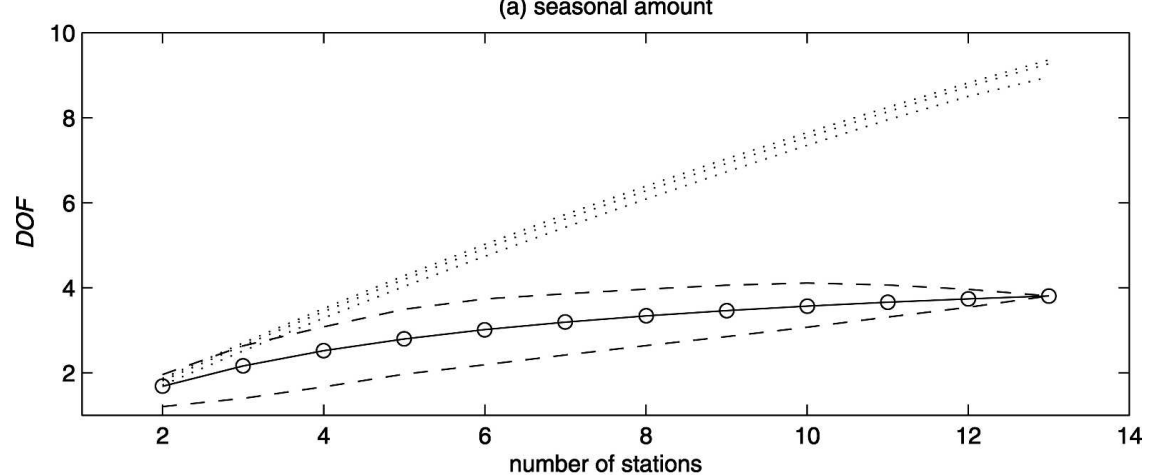

(b) occurence of rainfall

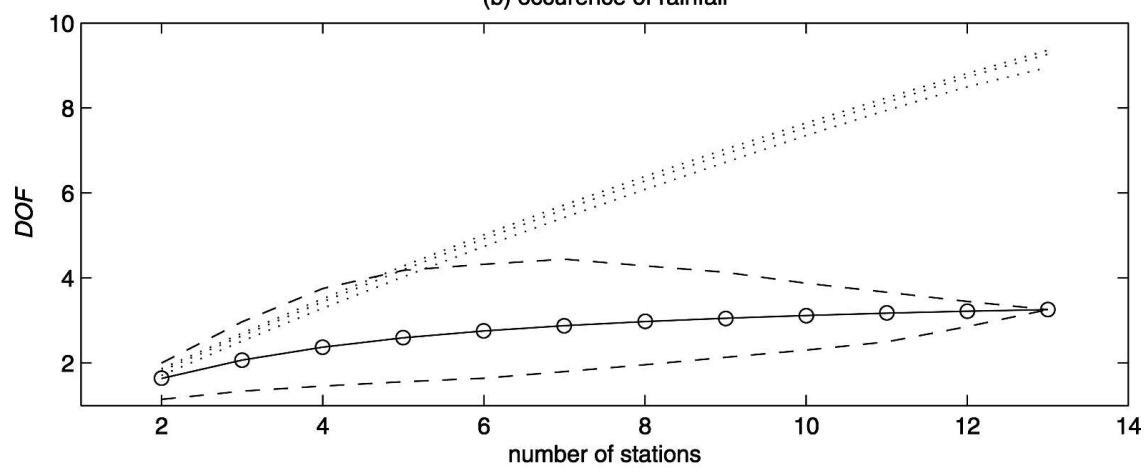

(c) mean intensity of rainfall

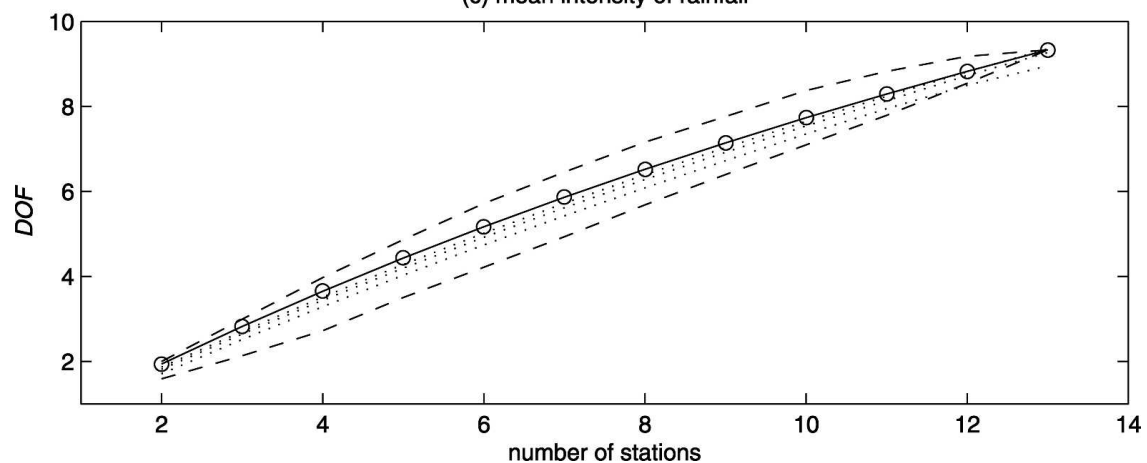

FIG. 4. Mean (solid line with circles) and minimum and maximum (dashed lines) of degrees of freedom (DOF) of all the combinations (from 2 to 13 stations) of (a) the seasonal amount, (b) rainfall occurrence, and (c) mean intensity of the 13 stations of the Senegal's network. There are 78, 286, 715, 1287, 1716, 1716, 1287, 715, 286, and 78, respectively, and 13 possible combinations of $2,3,4,5,6,7,8,9,10,11$, and 12 stations, respectively. The dotted lines give the $0.1,0.05$, and 0.01 levels of significance estimated from 100 random matrices of the same size as Senegal network ( 38 observations by 13 variables, which are independent from each other).

the skill at the individual stations is high; with an EVR of $10 \%$, the individual skill varies between -0.33 and 0.77 (the 25th and 75th percentiles are 0.21 and 0.41 , respectively). This range underscores the challenge in interpreting differences in correlation skill across stations in downscaling predictability studies. The ranges here are achieved with the same background level of skill, and are attributable purely to sampling error, so that with longer series, skill in all individual series would be the same, tending to the square root of EVR. Figure 5b shows the "mean skill" in terms of the 13station average of each station's correlation. The mean skill must converge toward the square root of EVR and is seen to do so very rapidly as EVR increases (Fig. 5b). 

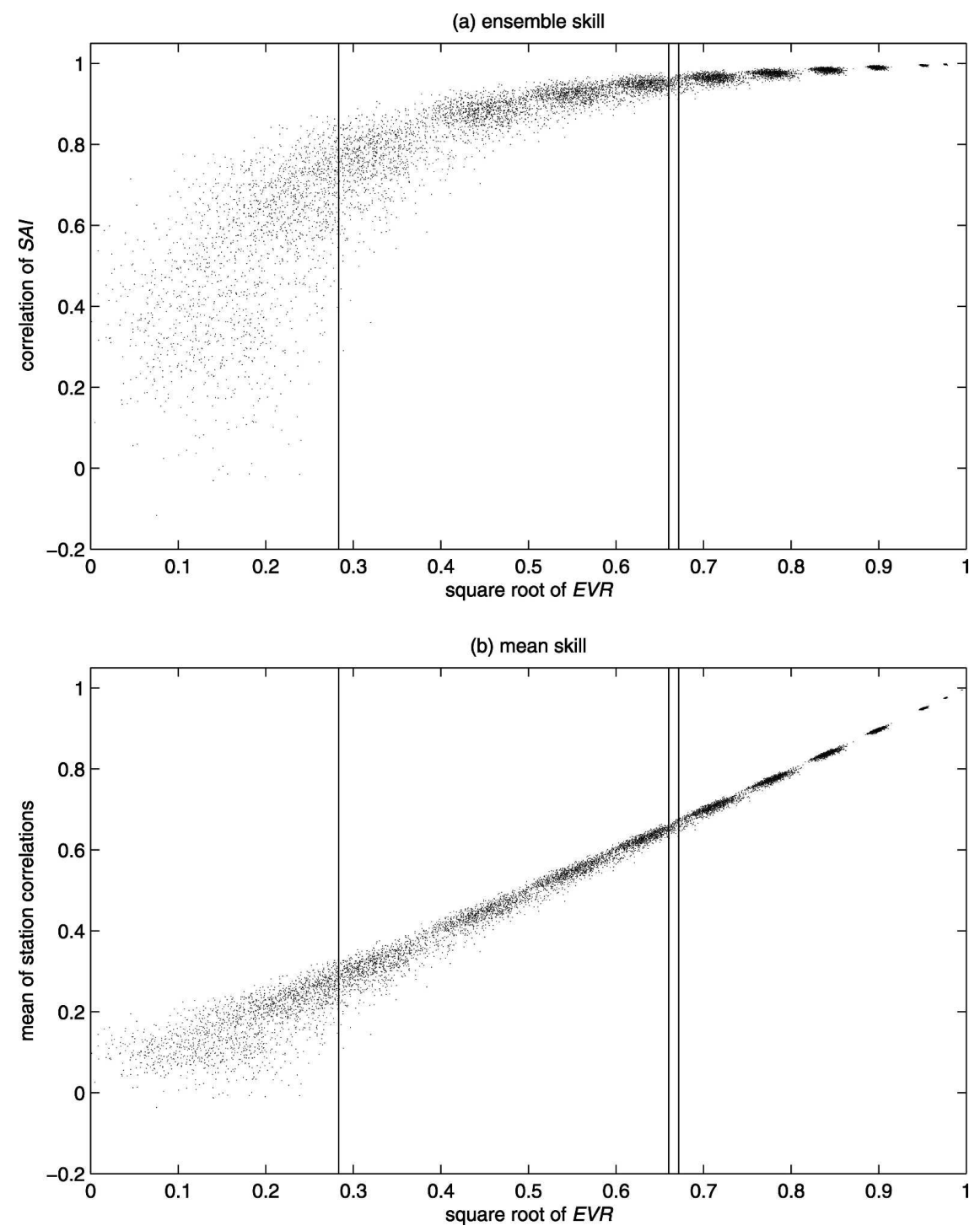

FIG. 5. Skill (temporal correlation between each column of $\mathbf{X}$ and $\mathbf{f}$ time series) vs the square root of EVR of $\mathbf{X}$ for the 13000 simulations of the random matrices of the same size as Senegal in case where $\mathbf{X}=$ If $+\mathbf{N}$. (a) Ensemble skill (temporal correlation between SAI of $\mathbf{X}$ and $\mathbf{f}$ ) and (b) mean skill (mean of the temporal correlation between each column of $\mathbf{X}$ and $\mathbf{f}$ ). The values are computed for an EVR of $1 \%, 5 \%, 10 \%, 20 \%, 30 \%, 40 \%, 50 \%, 60 \%, 70 \%, 80 \%$, $90 \%, 95 \%$, and $99 \%$. The vertical lines indicate the empirical square root of EVR of seasonal amount, rainfall occurrence, and mean intensity (Table 1).

This above example is clearly ideal, since we assume that the signal is equal to $\mathbf{f}$, which is assumed to be known. The same theoretical example is now repeated by adding a certain amount of random white noise $\boldsymbol{v}$ to f [i.e., $\mathbf{C}=\mathbf{I}(\mathbf{f}+\boldsymbol{v})]$, representing $20 \%, 40 \%, 60 \%$, and $80 \%$ of the total variance of $\mathbf{f}$. Adding a large amount of noise would be analogous to recognizing that the large-scale climate forcing field actually contained little potential predictability from SST forcing, such as for the NAO. The percentiles of the individual correlations between each column of $\mathbf{X}$ and $\mathbf{f}$ for an EVR of $\sim 8 \%$ (typical of $I$ ) and $\sim 44 \%$ (typical of $S$ and $O$ ) are displayed in Fig. 6. Adding noise to $\mathbf{f}$ logically decreases the correlations between $\mathbf{f}$ and each station. It also increases the sampling variability for high EVRs, given by the range of values. This increase is clearly stronger for an EVR of $\sim 44 \%$ (Fig. 6 b) than for an EVR $\sim 8 \%$ (Fig. 6a). If we define a skill of 0.4 as "useful," respectively $99.9 \%, 97.7 \%, 85.3 \%, 55.4 \%$, and $10.8 \%$ of the individual correlations are above such a skill with a 
(a) individual correlations for an EVR of $7.5-8.5 \%$

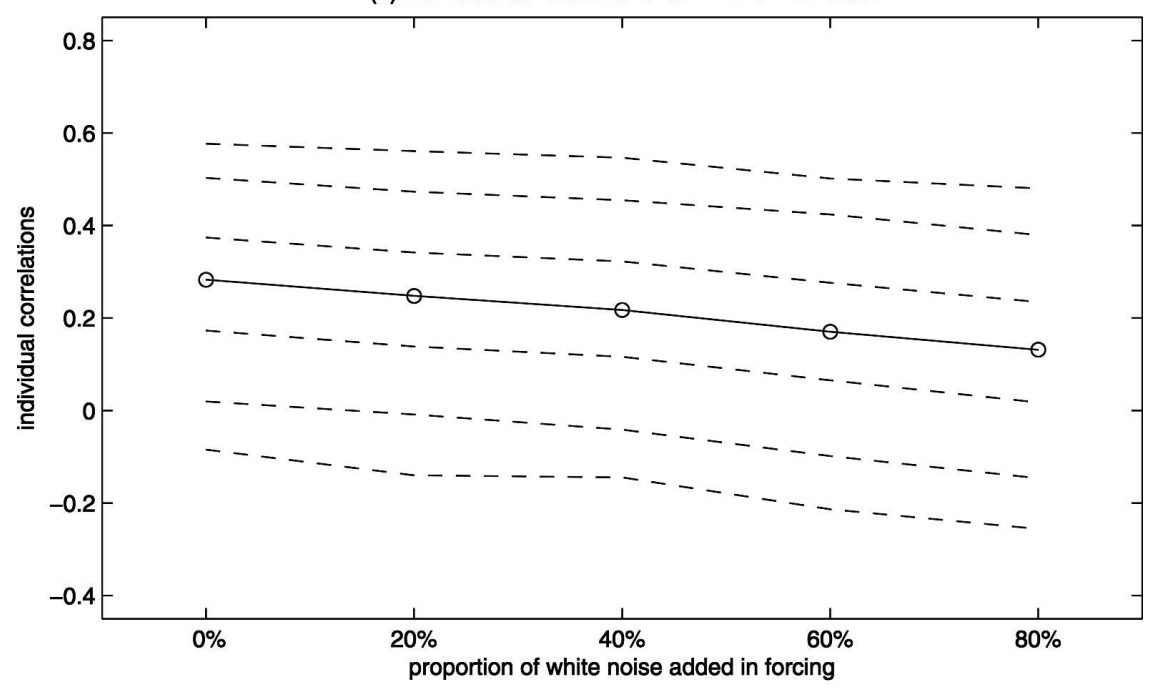

(b) individual correlations for an EVR of $43-45.5 \%$

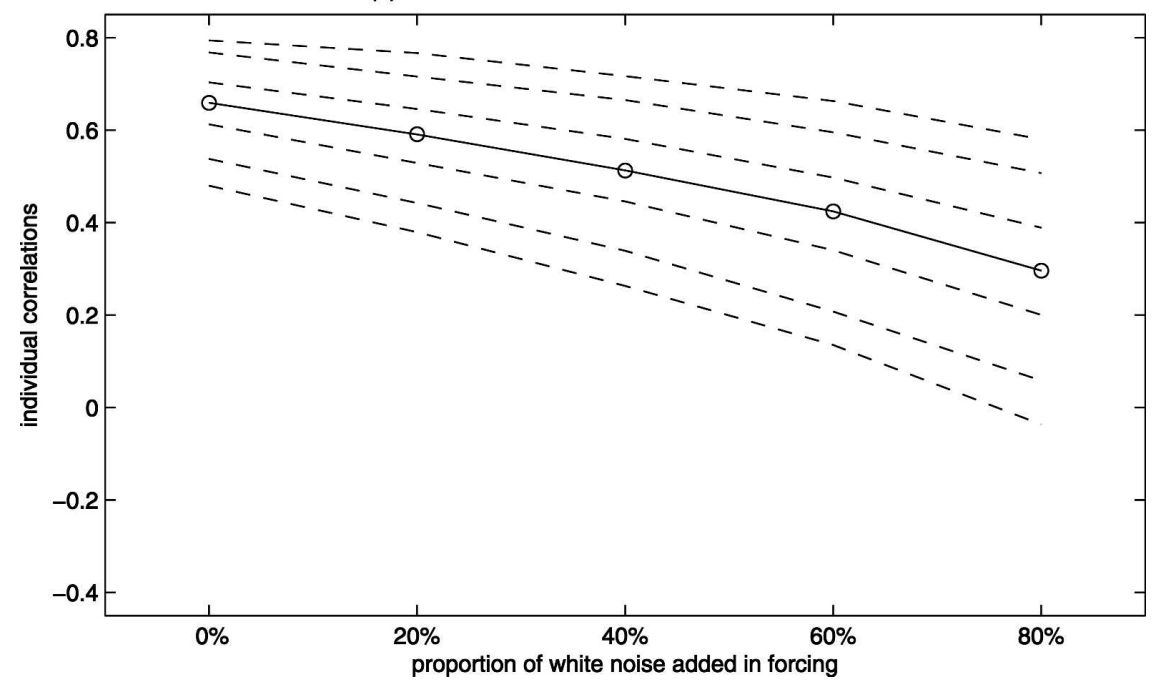

FIG. 6. Median (line with circles) and 1\%, 5\%, 25\%, 75\%, 95\%, and 99\% percentiles (dashed lines) of the individual skill (temporal correlations between each column of $\mathbf{X}$ and $\mathbf{f}$ time series) vs the amount of white noise $(\boldsymbol{v})$ added in $\mathbf{f}$ in case, where $\mathbf{X}=\mathbf{I}(\mathbf{f}+\boldsymbol{\nu})+\mathbf{N}$. One thousand random simulations are performed with $\boldsymbol{v}$ accounting for $0 \%, 20 \%, 40 \%, 60 \%$, and $80 \%$ of the temporal variance of $(\mathbf{f}+\boldsymbol{\nu})$ time series for an (a) EVR between $7.5 \%$ and $8.5 \%$ (typical of mean intensity of rainfall) and (b) EVR between $43 \%$ and $45.5 \%$ (typical of seasonal amount and rainfall occurrence).

proportion of $0 \%, 20 \%, 40 \%, 60 \%$, and $80 \%$ of noise added in $\mathbf{f}$ in case of an EVR of $\sim 44 \%$ (Fig. $6 b$ ).

\section{Potential predictability and skill provided by SST}

In this section, we compare the potential predictability inferred from the spatial coherence of station rainfall with the potential predictability and skill computed from a 24-member ensemble of GCM simulations forced by prescribed SST.
Table 2 shows the external variance ratio estimated at each GCM grid point corresponding approximately to Senegal (i.e., the four easternmost grid points of the box indicated in Fig. 1e; the two westernmost grid points of this box are located over ocean and not included here). The GCM's raw EVR estimates of potential predictability are qualitatively consistent with those inferred from spatial coherence, with the occurrence predictability 2.5-9 times larger than that of mean intensity of rainfall. This estimate does not take into ac- 
TABLE 2. GCM's EVR (\%) of $S, O$, and $I$ simulated at four continental grid points corresponding approximately to Senegal (i.e., the easternmost grid points in the box underlined in Fig. 1e). Mean intensity and occurrence are computed with GCM's days receiving more than $1 \mathrm{~mm}$. The SAI is computed as the mean of standardized anomalies of the four grid points of each run.

\begin{tabular}{llccr}
\hline \multicolumn{1}{c}{ Lat } & \multicolumn{1}{c}{ Lon } & $S$ & $O$ & \multicolumn{1}{c}{$I$} \\
\hline $12.5578^{\circ} \mathrm{N}$ & $14.0625^{\circ} \mathrm{W}$ & 27.7 & 33.9 & 13.3 \\
$12.5578^{\circ} \mathrm{N}$ & $11.25^{\circ} \mathrm{W}$ & 20.4 & 26.5 & 10.0 \\
$15.3484^{\circ} \mathrm{N}$ & $14.0625^{\circ} \mathrm{W}$ & 16.5 & 18.3 & 6.3 \\
$15.3484^{\circ} \mathrm{N}$ & $11.25^{\circ} \mathrm{W}$ & 13.5 & 15.3 & 6.0 \\
EVR of the SAI & & 22.4 & 28.4 & 11.4 \\
\hline
\end{tabular}

count any spatial bias in the GCM's rainfall anomalies over Senegal, and excludes sources of potential predictability other than SST.

The skill of the GCM simulation is first computed using the ensemble mean at the four continental points corresponding to Senegal (defined in Table 1 and Fig. 1e). The correlations between observed and simulated SAI are $0.24,0.36$, and -0.18 for $S, O$, and $I$, respectively. These values are lower than the potential predictability estimates in Table 2 would suggest, because an external variance of $22.4 \%$ given by the SAI of $S$ would correspond to a potential anomaly correlation of 0.47 . Several factors could lower the skill. A wellknown issue is that GCMs tend to displace the teleconnection patterns in space. Figure 7 shows the correlation between observed SAI of $S, O$, and $I$ and their simulated counterparts in the 24-member ensemble of the ECHAM-4.5 simulations. The ensemble mean is used here. The correlations are weak to moderate for $S$ (Fig. 7a) and $O$ (Fig. 7b) and weak for $I$ (Fig. 7c). Moreover, the highest values of each map are systematically shifted from the observed network, mainly along the Mauritanian coast for $S$ (Fig. 7a) and $O$ (Fig. 7b), and along the Sudanian belt near $12^{\circ} \mathrm{N}$ for $S$ (Fig. 7a) and $I$ (Fig. 7c). In other words, the best estimate of the observed rainfall variability of the 13 stations of Senegal is clearly shifted in the ECHAM-4.5 simulation. We remove this bias using a MOS correction, as described in section $2 b$.

The cross-validated MOS-corrected GCM skill values are displayed in Fig. 8, and are indeed much higher than without the MOS correction, and of the order of the potential predictability in Table 2. Skills are highest for $O$ (Fig. 8b) slightly exceeding $S$ (Fig. 8a). The geographical variation of skill is also coherent for $S$ (more skill over the central and northern part of the country and less skill for the southern forested area) and $O$ (more skill over the northern and western part of the country). Recalling the sampling ranges of skill variations that are possible with this length of historical rec- (a) correlation observed $S A I(S)$ vs simulated $S$

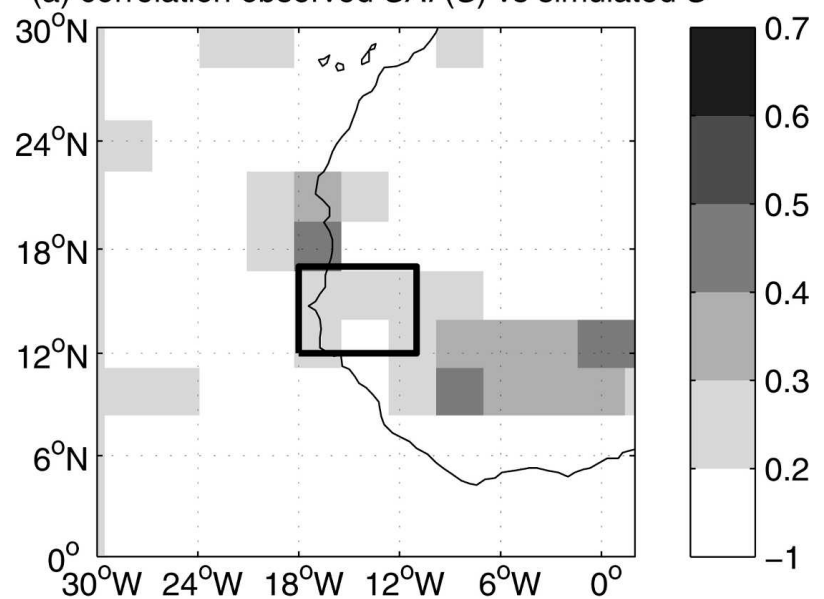

(b) correlation observed $S A I(O)$ vs simulated $O$

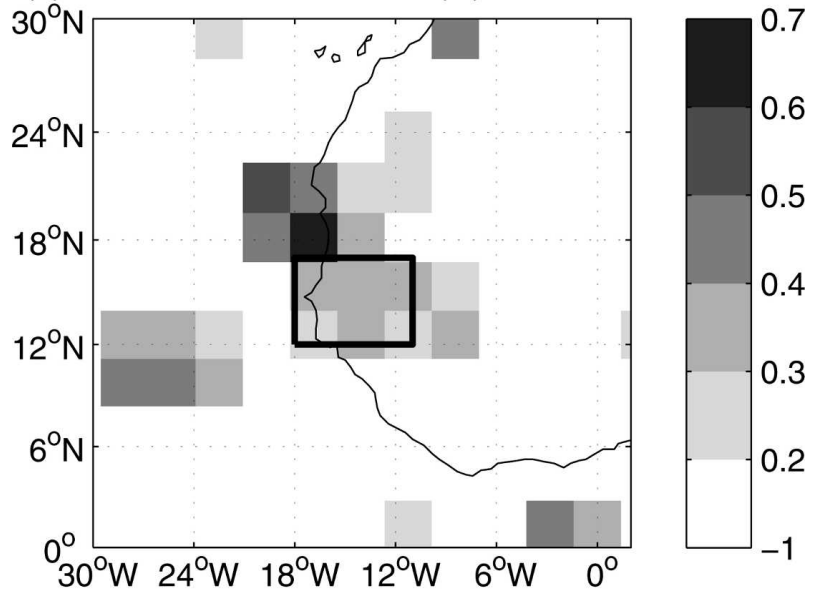

(c) correlation observed $S A I$ (I) vs simulated I

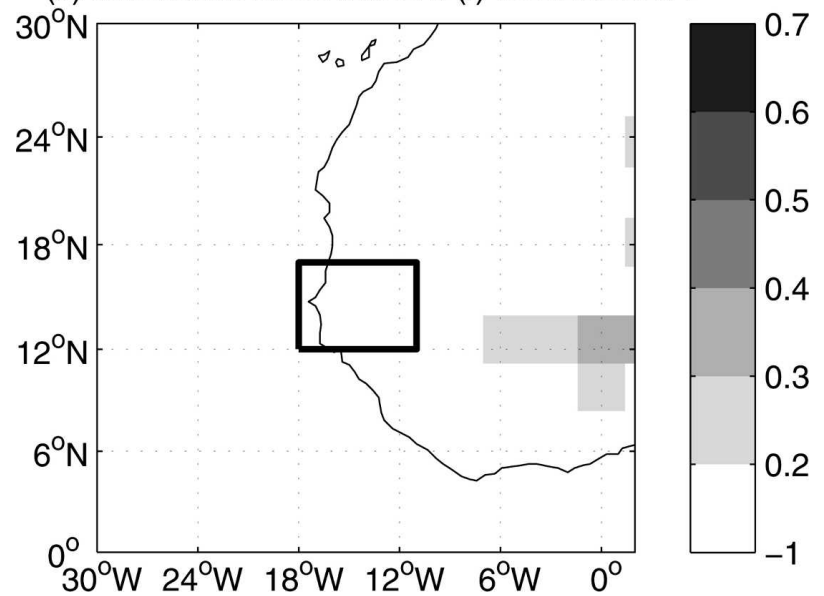

FIG. 7. Correlation between observed SAI (= country average of standardized anomalies) of (a) seasonal amount, (b) rainfall occurrence, (c) daily mean intensity of rainfall and the same quantities in the ensemble mean of ECHAM 4.5. In (b) and (c), the simulated occurrence and daily mean intensity of rainfall are computed only from simulated daily amounts $>1 \mathrm{~mm}$. The black box indicates the location of Senegal. 
(a) MOS skill of $S$ (4 CCA modes)

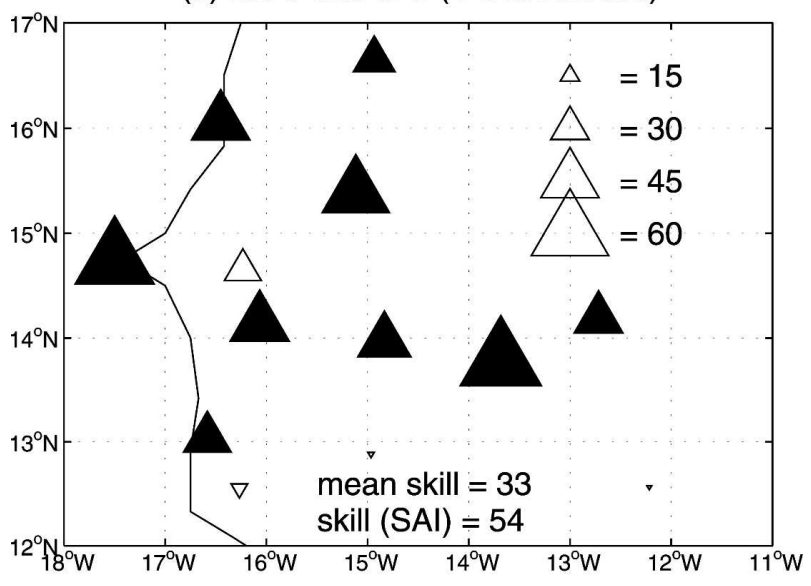

(b) MOS skill of $O$ (3 CCA modes)

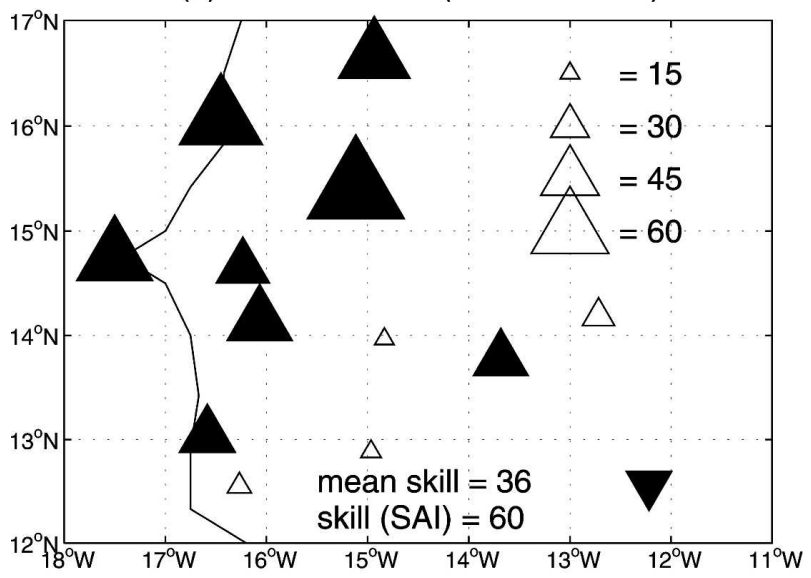

(c) MOS skill of $I$ (5 CCA modes)

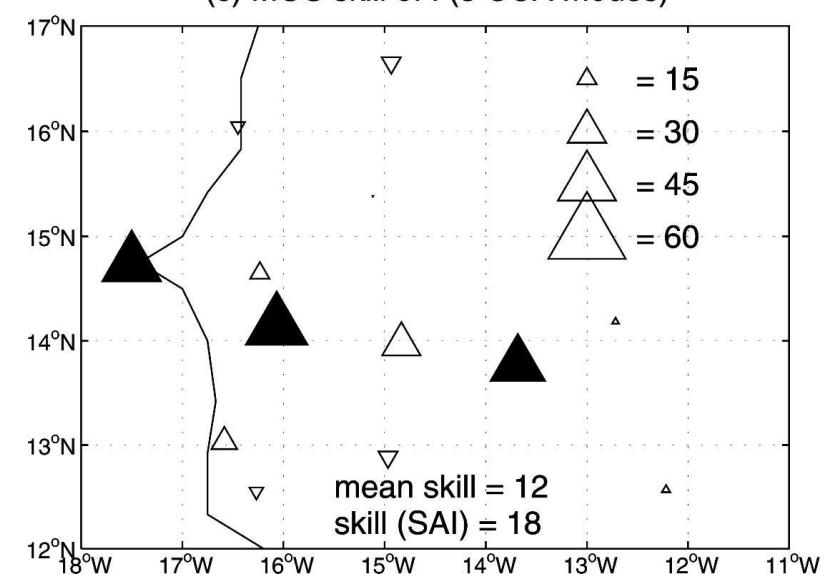

FIG. 8. Skill (= correlation $\times 100$ between observed and MOS corrected GCM time series) of (a) seasonal amount, (b) rainfall occurrence, and (c) daily mean intensity of rainfall. The MOS uses a cross-validated (5 $\mathrm{yr}$ are withheld at each turn) CCA between observed variables on the 13 -station network and simulated variables from the 24-member within the region $\left(0^{\circ}-30^{\circ} \mathrm{N}, 30^{\circ} \mathrm{W}-0^{\circ}\right)$. The number of CCA modes included in the MOS correction is indicated in the title of each panel. Upper triangle indicates positive correlations and lower triangle indicates negative correlations. The filled triangles are significant at the two-sided 0.1 level according to a random-phase test (Janicot et al. 1996; Ebisuzaki 1997). ord (Figs. 5-6), such spatial variations in skill would need to be justified in a physical term for them to be used with any confidence for forecasting.

The fact that three stations show significant skill for $I$ (Fig. 8c) is intriguing but may be due to sampling. We have applied the same hindcast scheme to the median rainfall amount on wet days, instead of the mean intensity; the median is less subject to sampling, compared with the mean, especially for dry stations where the number of wet days is small. Using the median yielded a severe decrease of skill; for example, using four CCA modes, the correlation between observed and MOScorrected simulated median rainfall amount lowers every correlation below 0.31 . In addition, simulated $I$ is almost always strongly positively correlated with simulated $O$ over the Sahelian belt (correlation $>0.7$ ). It is thus possible that some skill is artificially transmitted to $I$.

\section{Conclusions}

The primary motivation of this study was to explore the potential predictability of rainfall characteristics at regional and local scales. The method used here considers that, at the regional scale, the stations of a network can be treated as different members of an ensemble forced by the same large-scale forcing (such as global SST fields). In this context, each station shares a common variability-given by the area stationaveraged anomaly - referred to as signal, together with an independent component, referred to as noise. This simple hypothesis assumes that the regional impact of large-scale climate anomalies is uniform in space, which appears reasonable for a relatively small and flat country like Senegal. This assumption can be relaxed by considering a weighted mean (such as an EOF pattern), provided the weights remain constant in time. For the case of Senegal, the variance explained by the first EOF is only slightly greater than that of the average of standardized anomalies [i.e., the SAI; Table 1].

The seasonal rainfall amount, daily frequency of occurrence, and daily mean intensity of rainfall are, by definition, statistically related (Fig. 2). At the station scale, interannual anomalies of seasonal rainfall total are, on average, rather equally correlated with both occurrence and mean intensity. For area-averaged indices, the correlation of seasonal total with occurrence is high, whereas this is less the case for seasonal total with mean intensity. All the measures of spatial coherence examined (Table 1; Figs. 3-4) indicate that the amount of noise is larger for mean intensity, than for occurrence and seasonal amount. Thus, the contribution of mean intensity to interannual anomalies in amount is likely to be unpredictable. This is consistent 
with occurrence being more spatially coherent than amount.

The combinatorial analysis (Fig. 4) gives a measure of the unknown "true" number of spatial DOF of interannual variability, which can be interpreted as the dimensionality of the underlying attractor. The DOF of rainfall occurrence and seasonal amount is estimated to be between 3 and 4, and almost invariant on the number of stations considered (Figs. 4a,b). This is an important result: it translates into the number of stations that are necessary to accurately describe the spatiotemporal interannual variability of these quantities in Senegal. The estimated DOF of daily mean intensity of rainfall, on the other hand, is found to increase almost linearly with the number of stations considered. The empirical DOF of daily mean intensity should be viewed as a lower limit, and would be expected to increase for a denser network. It also implies that the network is too sparse to accurately sample interannual variability of daily mean intensity; thus, potential predictability of daily mean intensity at smaller spatial scales than those analyzed here cannot be ruled out. Our results have important implications for downscaling of GCM simulations to station scales; for example, where this distinction between occurrence and mean intensity predictability applies, it may prove useful to concentrate particularly on achieving a good estimate of occurrence, and to partly treat mean intensity as a stochastic process.

The difference in potential predictability between the three variables makes sense from both statistical and physical points of view. In dry climates, the daily mean intensity of rainfall is heavily influenced by a few large events, whose details are controlled by small-scale features of cumulus convection. Very strong variability was observed at daily or subdaily time scales during the Hydrologic Atmospheric Pilot Experiment in the Sahel experiment (D'Amato and Lebel 1998; Lebel et al. 2003). These events can influence the seasonal totals (Fig. 2b), but they are spatially incoherent, even statistically, and are thus not likely to be predictable. Occurrence frequency, on the other hand, is less prone to sampling (Snijders 1986).

The second goal of the paper was to investigate if a set of GCM simulations were consistent with the inferences about potential predictability and skill drawn from the spatial coherence analyses of the observations. The results are overall remarkably consistent with those inferred from the observed analysis of spatial coherence. The 24-member ECHAM-4.5 GCM (after MOS correction) is found to have a moderate-to-strong cross-validated skill at reproducing the interannual variations in the 13-station average rainfall occurrence (correlation $=0.60)$ and seasonal amounts (correlation $=0.54$; Fig. 8). At the individual station level, the maximum interannual correlation found between simulation and observation is 0.75 for the occurrence and 0.63 for the seasonal amount. The skill is highest in the central and northern part of the country and drops to insignificant values in the southern part of the country. Further study is needed to determine whether the source of this decrease is related to, for example, details of the local vegetation types, spatial changes in the expression of the large-scale dynamics of the teleconnection processes, or simply statistical sampling error such that for longer time series, the skill level would, in fact, be uniform over the domain of study.

For the daily mean intensity, the skill is close to zero, except at three stations. Our results indicate that the apparent skill at these stations may be an artifact of sampling variability (Figs. 5-6). Considering the median rainfall amount on wet days, instead of the mean, reduces the skill to near zero at all stations. Despite the above finding that daily mean intensity is largely unpredictable, the observed interannual changes in daily mean intensity at the station scale can be strongly correlated with seasonal amount at the station scale (Fig. 2b). The inference is that the variance of the seasonal rainfall total that is related to daily mean intensity will belong mostly to the unpredictable component of the variance in the seasonal total. Or put the another way, daily mean intensity is substantially correlated with the unpredictable component of the seasonal rainfall total.

This paper has developed some methodological approaches for exploring predictability of rainfall characteristics, and applied them in one particular setting. Clearly, it will be interesting to apply such analyses in different meteorological and topographic settings to establish the generalizability of results, and explore issues across zones that are more heterogeneous in topography than the one studied here. It would also be interesting to analyze longer data records. The current network contains only a few years in the pre-1968 wet period, preventing the investigation of possible decadal modulation of the spatial coherence. Further insight can be expected from studies in particularly data-rich situations where issues of spatial scale can be more closely addressed, compared with the approach here, that has been confined to contrasting the point scale, with the regional average.

Acknowledgments. We thank DMN-Senegal through Ousmane Ndiaye for providing the daily rainfall dataset for Senegal, and Pierre Camberlin (CRC, Dijon, France) for his insightful comments. The authors acknowledge the support of the U.S. National Oceanic 
and Atmospheric Administration through a Cooperative Agreement (NA07GPO213). Last, we thank David Schultz and the five reviewers for their comments and suggestions that substantially improved the paper.

\section{REFERENCES}

Barnett, T. P., and R. Preisendorfer, 1987: Origins and levels of monthly and seasonal forecast skill for United States surface air temperature determined by canonical correlation analysis. Mon. Wea. Rev., 115, 1825-1850.

Box, G. E. P., and D. R. Cox, 1964: An analysis of transformations. J. Roy. Stat. Soc., 127A, 211-252.

Bretherton, C. S., M. Widmann, V. P. Dymnikov, J. M. Wallace, and I. Bladé, 1999: The effective number of spatial degrees of freedom of a time-varying field. J. Climate, 12, 1990-2009.

Camberlin, P., and M. Diop, 1999: Inter-relatiomships between groundnut yield in Senegal, interannual rainfall variability and sea surface temperature. Theor. Appl. Climatol., 63, 163181.

D'Amato, N., and T. Lebel, 1998: On the characteristics of the rainfall events in the Sahel with a view to the analysis of climatic variability. Int. J. Climatol., 18, 955-974.

Der Megredichtian, G., 1979: L'optimisation du reseau d'observation des champs meteorologiques. La Météorologie, VI, 51-66.

Ebisuzaki, W., 1997: A method to estimate the statistical significance of a correlation when the data are serially correlated. $J$. Climate, 10, 2147-2153.

Fraedrich, K., C. Ziehmann, and F. Sielmann, 1995: Estimates of spatial degrees of freedom. J. Climate, 8, 361-369.

Gates, W., 1992: The Atmospheric Model Intercomparison Project. Bull. Amer. Meteor. Soc., 73, 1962-1970.

Gong, X., A. G. Barnston, and M. N. Ward, 2003: The effect of spatial aggregation on the skill of seasonal rainfall forecasts. J. Climate, 16, 3059-3071.

Hogg, R. Y., and A. T. Craig, 1970: Introduction to Mathematical Statistics. Macmillan, 475 pp.

Ingram, K. T., M. C. Roncoli, and P. H. Kirshen, 2002: Opportunities and constraints for farmers of West Africa to use seasonal rainfall forecasts with Burkina-Faso as a case study. Agric. Syst., 74, 331-349.

Janicot, S., V. Moron, and B. Fontaine, 1996: Sahel drought and ENSO dynamics. Geophys. Res. Lett., 23, 515-518.

Katz, R. W., and M. H. Glantz, 1986: Anatomy of a rainfall index. Mon. Wea. Rev., 114, 764-771.

Kebe, C. M. F., H. Sauvageot, and A. Nzeukou, 2005: The relation between rainfall and area-time integrals at the transition from an arid to an equatorial climate. J. Climate, 18, 38063819.

Laurent, H., N. D'Amato, and T. Lebel, 1998: How important is the contribution of the mesoscale convective complexes to the Sahelian rainfall? Phys. Chem. Earth, 23, 629-633.

Le Barbe, L., and T. Lebel, 1997: Rainfall climatology of the HAPEX-Sahel region during the years 1950-1990. J. Hydrol., 188-189, 43-73.
, and D. Tapsoba, 2002. Rainfall variability in West Africa during the years 1950-90. J. Climate, 15, 187-202.

Lebel, T., A. Diedhiou, and H. Laurent, 2003: Seasonal cycle and interannual variability of the Sahelian rainfall at hydrological scales. J. Geophys. Res., 108, 8389, doi:10.1029/2001JD001580.

Leith, C. E., 1974: Theoretical skill of Monte Carlo forecasts. Mon. Wea. Rev., 102, 409-418.

Madden, R. A., 1976: Estimates of natural variability of timeaveraged sea level pressure. Mon. Wea. Rev., 104, 942-952.

Marshall, J., and Coauthors, 2001: North Atlantic climatic phenomena, impacts and mechanisms. Int. J. Climatol., 21, 18631898.

Mathon, V., and H. Laurent, 2001: Life cycle of Sahelian mesoscale convective cloud systems. Quart. J. Roy. Meteor. Soc., 127, 377-406.

Moron, V., 1994: Guinean and Sahelian rainfall anomaly indices at annual and monthly time scales (1933-1990). Int. J. Climatol., 14, 325-341.

—, A. Navarra, and M. N. Ward, 2001: Observed and SSTforced seasonal rainfall variability across Tropical America. Int. J. Climatol., 21, 1567-1601.

Nzeukou, A., and H. Sauvageot, 2002: Distribution of rainfall parameters near the coasts of France and Senegal. J. Appl. Meteor., 41, 69-82.

Robertson, A. W., S. Kirshner, P. Smyth, B. Bates, and S. Charles, 2006: Subseasonal-to-interdecadal variability of the Australian monsoon over North Queensland. Quart. J. Roy. Meteor. Soc., 132, 519-542.

Roeckner, E., and Coauthors, 1996: The atmospheric general circulation model ECHAM4: Model description and simulation of present-day climate. Max Planck Institut für Meteorologie Rep. 218, Hamburg, Germany, 90 pp.

Rowell, D. P., 1998: Assessing potential seasonal predictability with an ensemble of multidecedal GCM simulations. J. Climate, 11, 109-120.

_ C. K. Folland, K. Maskell, and M. N. Ward, 1995: Variability of summer rainfall over tropical North Africa (1906-1992). Quart. J. Roy. Meteor. Soc., 121, 669-704.

Snijders, T. A. B., 1986: Interstation correlations and nonstationarity of Burkina-Faso rainfall. J. Climate Appl. Meteor., 25, 524-531.

Sperber, K. R., and T. N. Palmer, 1996: Interannual tropical rainfall variability in general circulation model simulations associated with the Atmospheric Model Intercomparison Project. J. Climate, 9, 2727-2750.

Venzke, S., M. R. Allen, R. T. Sutton, and D. P. Rowell, 1999: The atmospheric response over the North Atlantic to decadal changes in sea surface temperature. J. Climate, 12, 2562-2584.

Ward, M. N., and A. Navarra, 1997: Pattern analysis of SSTforced variability in ensemble GCM simulations: Example over Europe and the West Pacific. J. Climate, 10, 2210-2220.

Zwiers, F. W., 1987: A potential predictability study conducted with an atmospheric general circulation model. Mon. Wea. Rev., 115, 2957-2974.

_ 1996 : Interannual variability and predictability in an ensemble of AMIP climate simulations conducted with the CCC GCM2. Climate Dyn., 12, 825-847. 